Max-Planck-Institut für demografische Forschung

Max Planck Institute for Demographic Research

Konrad-Zuse-Strasse 1 - D-18057 Rostock · GERMANY

Tel +49 (0) 3812081 - 0; Fax +49 (0) 3812081 - 202;

http://www.demogr.mpg.de

MPIDR WORKING PAPER WP 2007-034

NOVEMBER 2007

\title{
High fertility in city suburbs: compositional or contextual effects?
}

Hill Kulu (kulu@demogr.mpg.de)

Paul J. Boyle

(C) Copyright is held by the authors.

Working papers of the Max Planck Institute for Demographic Research receive only limited review. Views or opinions expressed in working papers are attributable to the authors and do not necessarily reflect those of the Institute. 


\begin{abstract}
Fertility rates are known to be higher in city suburbs. One interpretation is that the suburban 'context' influences the behaviour of individuals who reside there while an alternative is that the 'composition' of the suburban population explains the higher fertility levels. Furthermore, suburban in-migrants who intend to have children may have a significant influence on suburban fertility rates. Using Finnish longitudinal register data we show that fertility rates are higher in the suburbs and rural areas and lower in the cities. While fertility variation across these residential contexts decreases significantly after controlling for women's demographic and socio-economic characteristics, it does not disappear entirely suggesting that the local context may have some influence on fertility. While movers to suburbs do display higher fertility levels than non-migrant residents, their overall impact is not great because they form a small share of the suburban population.
\end{abstract}

Keywords: fertility; migration; residential mobility; urban, suburban and rural; event history analysis; Finland 


\section{Introduction}

In the context of enduring low fertility across most of Europe, two broad research strategies can be identified. First, a considerable literature has focused on the individual and household characteristics which may explain fertility behaviour. Thus we know much about the role of demographic factors, such as the changing rates of marriage, cohabitation and separation (Kohler et al. 2002), which have accompanied the 'second demographic transition' (van de Kaa 1987). The role of women's socio-economic characteristics, such as their labour market engagement (Andersson 2000, Engelhardt et al. 2004) and educational engagement and attainment (Hoem et al. 2006a, 2006b), as well as ideational shifts that influence attitudes to gender roles and childbearing (Surkyn and Lesthaeghe 2004, van de Kaa 2001), have also been implicated in explaining fertility intentions and behaviour.

Second, it has also been recognised that focusing entirely on individual circumstances is inadequate as fertility behaviour will be influenced by national institutional structures, policies and attitudes (Aassve et al. 2006, Blossfeld and Rohwer 1995, Hoem 1990, 1993b, Neyer and Andersson 2004). While some argue that national variations in fertility are narrowing and that convergence will likely occur (Wilson 2001), others maintain that national differences persist and are unlikely to diminish considerably in the near future. Thus, Coleman (2002) and Frejka and Calot (2001) point to persisting differences in fertility behaviour which may be linked, in part at least, to continuing national differences in other related processes such as female labour force participation and the age at leaving the parental home (Billari and Kohler 2004). Certain European countries, such as Spain and Italy, have experienced lowest-low fertility for some time, while birth rates in countries in northern and western Europe have remained persistently higher, although still below replacement levels. Explaining these national differences is not a simple matter and Caldwell and Schindlmayr (2003) argue that relatively simple models which focus on welfare systems or family structures are too restrictive, and they emphasize the complex array of contextual variables which may contribute to historical and geographical differences in fertility.

Given this background, where there has been considerable interest among demographers in cross-national variations in fertility and the 'convergence debate', it is perhaps remarkable that so little research has explored fertility variations within nations. Boyle (2003) argues that while the exploration of local variations in fertility behaviour may 
provide useful clues in our understanding of fertility processes and outcomes, relatively few studies of this type exist in the contemporary European context. This is in contrast to the considerable body of historical research which demonstrates persuasively the importance of the local environmental context in explaining changes in fertility behaviour around the time of the 'first demographic transition'. A major finding of the Princeton European Fertility Project was that fertility decline followed distinct spatial patterns within countries (Coale and Watkins 1986). It also showed that urban fertility (both marital and overall) was lower than rural fertility prior to the demographic transition, and during the transition it decreased earlier and more rapidly (Sharlin 1986). Garrett et al. (2001), in turn, demonstrated that fertility reduction in nineteenth century England was not prompted by a single underlying cause which swept through society as a whole, because individuals in similar social classes and occupations were shown to have very different fertility rates depending on where they lived. Szreter (1996) emphasized the importance of community-level values and attitudes which helped to explain variations in courtship, marriage and childrearing patterns in what he termed 'communication communities'. Thus, distinct social, cultural and community groups altered their reproductive regimes in different ways depending on the unique environmental context (Szreter and Garrett 2000).

Those few recent studies which have examined contemporary geographical fertility variations within countries have also tended to focus on broad urban-rural differences, with the overriding conclusion being that fertility rates are significantly lower in urban or metropolitan areas. This is the case in France (Fagnani 1991), Italy (Michielin 2004), Estonia (Kulu 2005), West Germany (Hank 2001), the Netherlands (Mulder and Wagner 2001), Austria and Poland (Kulu 2006), Denmark, Finland, Norway and Sweden (Kulu et al. 2007b) and the US (Heaton et al. 1989). Thus, contemporary research confirms that there are significant urban-rural differences in fertility behaviour, across a number of countries, apparently regardless of whether they are medium, low or lowest-low fertility nations. And, in some of these studies at least, these effects were demonstrated while controlling for individual socio-economic characteristics expected to influence fertility behaviour.

While these urban-rural analyses shed considerable light on important variations in fertility behaviour, they could also be argued to be geographically crude. A small body of early studies drew attention to noticeably higher fertility rates in the suburbs of urban areas (Goldstein and Mayer 1965, Grabill et al. 1958, Mayer and Klapprodt 1955, Weller 
and Bouvier 1972). Indeed, it was argued that suburban environments were especially conducive for childrearing and that family planning was a major influence on those who joined the swelling number of suburban residents:

"While the migration to the suburbs has been in part fuelled by a desire to escape the mix of classes and ethnic groups of urban areas, and by government- and market-shaped economic incentives, the suburban ideal has stressed finding an environment in which family ties can be strengthened" (Miller 1995: 393)

More recently, we can find virtually no studies which compare urban, suburban and rural fertility patterns in contemporary Europe (although there has been some interest in these issues in North America; see Albrecht and Albrecht 2004, Heaton et al. 1989, Snyder 2006). Two recent European studies suggest that contemporary suburban fertility continues to be higher than in urban areas and, in some instances, even higher than in rural areas. Kulu et al. (2007a) show that in the Nordic countries fertility rates in the suburbs of smaller cities and towns have risen close to those in rural areas. Boyle et al. (2007) use a different approach where they seek significant geographical clusters of fertility within Scotland, controlling for factors expected to influence fertility. Their results identify significant clusters of low fertility in central cities, but also substantial clusters of high fertility in the suburbs and nearby extra-urban surrounds.

Why fertility rates have been, and continue to be, significantly higher in suburban than urban areas is an interesting theoretical question and three possible hypotheses may be posited. First, the demographic and socio-economic characteristics of those living in suburbs will be different to those living in urban areas. For example, compared to central cities, there tend to be fewer single people and students in the suburbs. These factors therefore relate to the composition of the suburban population, relative to other groups. Second, suburbs are usually regarded as more suitable residential contexts for families than inner city areas, as they tend to have larger houses, gardens, open areas and better schools, as well as less congestion, crime and pollution. Suburban residents are more likely to be surrounded by families with children and local cultural norms and attitudes (what some might refer to as a 'modern rurality') may also influence fertility, such that women's behaviour is different to that which would be expected based solely on her personal or household characteristics. Thus, the residential context may have an independent influence over fertility decision-making and according to this hypothesis the fertility behaviour of those moving into the suburbs will be expected to become more 
similar to the dominant behaviour at the destination over time. This adaptation effect has been supported in previous studies of internal migration (e.g. Goldstein 1973, Kulu 2005, Myers and Morris 1966). Finally, it is also possible that there is a migrant selection effect (Courgeau 1989). City dwellers planning to start, or having just embarked on, childbearing may decide to move to suburban locations because of the perceived suitability of the environment for childrearing. Thus, while the residential context may have influenced the decision to move, it is not the experience of living there which promotes childbirth; rather childbearing intentions promote residential mobility into suburban areas. Such selection processes have been identified before; for example, Andersson (2004) and Milewski (2006) found that moving triggered childbirth among recent immigrants to Sweden and Germany, respectively, while Kulu and Vikat (2007) identified elevated fertility levels for couples moving to single-family houses in Finland.

The analysis we present here of fertility behaviour in Finland is the first to consider the importance of these opposing hypotheses in relation to urban, suburban and rural fertility. Using event history analysis, we model the hazard of first, second and third birth among partnered women in different residential contexts, controlling for a range of individual characteristics expected to influence fertility. Our aim is to test the relative importance of the composition, context and selection hypotheses.

\section{Data}

The data come from the Finnish Longitudinal Fertility Register. This is a database developed by Statistics Finland, which contains linked individual-level information from different administrative registers (for details, see Vikat 2004). The extract we used in the analysis included women's full birth and educational histories. Partnership and residential histories and annually measured characteristics about women's economic activity and income were collected for the period from 1987 to 2000. The extract used is a ten-percent random sample stratified by single-year birth cohort, drawn from records of all women who had ever received a personal identification number in Finland and were in the age range 16 to 49 for some time between 1988 and 2000 (cohorts born between 1938 and 1983). We focused on childbearing among women who were in unions and included in the analysis all co-residential unions that were formed between 1988 and 2000. Foreignborn women (three percent) and residential episodes of Finnish-born women who were abroad were also excluded from the analysis. 
We studied the impact of residential context on first, second and third birth. We distinguished three types of residential contexts according to the size of the municipality of residence: 1) the capital city (Helsinki); 2) other cities (with 50,000-250,000 inhabitants) and towns (with 10,000-50,000 inhabitants); 3) rural areas (municipalities with less than 10,000 inhabitants). Additionally, we distinguished between central cities and suburban areas for cities and towns with more than 30,000 people ${ }^{1}$. When defining suburbs we followed a definition developed by Statistics Finland where a municipality was assigned to an urban centre if at least $10 \%$ of its employed population commuted there in 2000. Using commuting data to define 'travel-to-work' or labour-market regions is standard in migration and urbanisation research, although the threshold used varies across studies (see Champion 2001; Hugo et al. 2003).

Table 1 presents the distribution of person-years (exposures) and events (occurrences) across various residential contexts by risk of first, second or third birth. The person-years for a particular individual could have included spells in a number of different geographical categories over time as a result of migration. The largest residential category for the first birth was the centres of 'other cities and towns' $-44 \%$ of all personyears were in this residential category. This was followed by the centre and suburbs of Helsinki with $17 \%$ of total person-years in each. Thirteen percent of the person-years for the first birth were in the suburbs of 'other cities and towns', and nine percent in rural areas. A similar pattern was observed for the second and third birth, although the share of person-years in the suburbs and rural areas increased compared to first birth. Note that person-years for migrants formed a relatively small share of total person-years, although it increased with parity.

Table 1 also provides information on the distribution of births by residential context. There were 14,282 first births for 35,391 women, 12,090 second births for 23,154 women and 4,099 third births for 17,246 women in the data. While childless women who formed a union between 1988 and 2000 made up the population at risk for first birth, the data-set for second and third births also included women who had their first or second conception (leading to birth) in 1988 or later, but before union formation, and women who had their

\footnotetext{
${ }^{1}$ The municipalities with population less than 30,000 people were assigned into the category 'other cities and towns, centre'.
} 
first or second conception (leading to birth) before 1988, but formed another union in 1988 or later.

In the modelling, we explored geographical variations in fertility, controlling for a set of demographic and socio-economic variables expected to influence childbearing. Our demographic controls included: union duration, woman's age, the age of the youngest child (if there were any), calendar time and whether it was marital or cohabiting union. The socio-economic controls included women's educational enrolment (not enrolled or enrolled), educational level (lower secondary, upper secondary, vocational, lower tertiary or upper tertiary) and annual earnings (none, low, medium, high or very high). A particularly important aspect of the residential environment expected to influence fertility behaviour was housing type and we distinguishing between single-family houses, terraced houses and apartments.

\section{Methods}

We used a multivariate event history analysis (Blossfeld and Rohwer 1995, Hoem 1987, 1993a), fitting a series of regression models for the hazard of first, second and third birth. We modelled the time to conception (which subsequently led to a birth) in order to measure the effect of residential context on childbearing decisions as precisely as possible. The basic model can be expressed as:

$$
\ln \mu_{i}(t)=y(t)+\sum_{k} z_{k}\left(u_{i k}+t\right)+\sum_{j} \alpha_{j} x_{i j}(t)
$$

where $\mu_{i}(t)$ denotes the hazard of the first, second or third conception for individual $i$ and $y(t)$ denotes a piecewise linear spline that captures the impact of baseline duration on the hazard $^{2}$ (e.g. union duration). The parameter $z_{k}\left(u_{i k}+t\right)$ denotes the spline representation of the effect of a time-varying variable that is a continuous function of $t$ with origin $u_{i k}$ (e.g. woman's age). The parameter $x_{i j}(t)$ represents the values of a time-varying variable whose values can change only at discrete times (e.g. residential context or housing type).

\footnotetext{
${ }^{2}$ We used a piecewise linear spline specification (instead of the widely used piecewise constant approach) to pick up the baseline log-hazard and the effect of (other) time-varying variables that change continuously. Parameter estimates are thus slopes for linear splines over user-defined time periods. With sufficient nodes (bend points) piecewise linear-specification can efficiently capture any log-hazard pattern in the data.
} 
We fitted four models for first, second and third births. In the first model we controlled for the duration of the married or cohabiting union, age of the woman and age of the youngest child (if there were any) and examined the hazards of childbirth by residential areas, distinguishing between the five residential contexts described above. In the second model, we additionally controlled for the marital status of women and their socioeconomic characteristics to examine the extent to which fertility variation across residential contexts could be explained by these factors. In the third model we also controlled for housing type, while the fourth, final, model introduced a more detailed breakdown of residential context / migrant status. Thus, our focus was on the influence of residential context (particularly the suburbs), and mobility between these contexts, on fertility and we therefore divided residents in suburban areas into migrants and nonmigrants, distinguishing between those moving a short distance from the nearby city centre and those originating elsewhere. The aim was to examine the extent to which migrant fertility could account for potentially high suburban fertility rates. Further, for migrants, we examined the timing of childbearing after the move in more detail. We assumed that elevated conception levels shortly after the move and decreasing risk levels thereafter would be consistent with a migrant selection effect, while no initial rise in fertility following the move, but a gradual increase over time, would suggest an adaptation effect. A decreased risk shortly after the move, which gradually increased thereafter, would reflect a disruption effect.

\section{Results}

\section{Risk of first birth}

Table 2 presents the models for first conception. In Model 1, which controlled only for union duration and the age of the woman, the risk was lowest in central Helsinki but was significantly higher in the city's suburbs, at about the same level as for the centre of other cities and towns in Finland. The highest risk was in the suburbs of other cities and towns and in rural areas. There is clear evidence that the risk of first conception was higher in city suburbs than in the corresponding city centres.

It is possible, however, that these higher suburban fertility rates simply reflect the characteristics of the women living there, rather than a contextual effect. In Model 2, we 
therefore controlled for the marital status and socio-economic characteristics of women. The differences across the residential contexts were reduced considerably, but remained significant. A closer inspection showed that much of the decrease was attributable to marital status: married couples were over-represented in suburban and rural areas. In Model 3, we also controlled for housing type. The fertility differences between the couples living in various residential contexts further decreased, indicating that the more 'family-friendly' housing in suburban areas is associated with higher fertility levels. Nevertheless, women in suburban areas still had a higher risk of first conception than those living in the urban centres (the fertility differences between the urban centre and suburbs were significant for both Helsinki and for the other cities and towns).

In Model 4, we extended the residential environment variable to distinguish between migrants and non-migrants in suburban areas, separating migrants from the nearby city or town and those from elsewhere. Non-migrant couples in the suburbs had a higher risk of first conception than couples in urban centres, while for migrants the risk varied depending on their origin. Couples who had moved from the urban centres to the suburbs had a high risk of first conception, whereas couples who had moved to the suburbs of the cities and towns from other settlements displayed a relatively low risk.

To further explore the fertility behaviour of suburban in-migrants we considered the timing of first conception following migration (Figure 1). For migrants from Helsinki into its suburbs there was a clear spike in the risk around three months ( 0.25 year) after the move suggesting a strong migrant selection effect. The decision to move to the suburbs appeared to have been influenced by childbearing intentions for many in this group. On the other hand, an opposite disruption effect was apparent for migrants from other origins into these suburbs, as the risk fell significantly during the first three months following the move. This later group might have had longer-term plans that they would start a family, hence the move into a suburban location, but in the short term their move reduced the likelihood that they would have a first conception, compared to other groups. Thus, they chose a suburban destination that would suit family life but, unlike the migrants from central Helsinki, they do not appear to have been driven to move by imminent childbearing intentions and the move itself, or the factors which promoted it, reduced the chances of a birth occurring. Similar, but less pronounced effects operated for the suburbs of other cities and towns. Interestingly, however, the fertility risks for inmigrants became similar to those of non-migrant couples in the second year after the 
move, suggesting an adaptation effect for those couples whose move was not driven by childbearing intentions.

\section{Risk of second birth}

The results for second birth were similar to those for first birth, although the differences across various residential contexts were smaller. Model 5, Table 3, shows that couples in Helsinki had the lowest risk of second conception, while those in the city's suburbs had a considerably higher risk. Fertility levels in the other urban centres were higher than in Helsinki and couples in the suburbs of these cities and towns had a higher risk than those in the centres of the other towns and cities. The highest risk of second conception was in rural areas.

Controlling for women's demographic and socio-economic characteristics (Model 6, Table 3) and, particularly, housing type (Model 7, Table 3) reduced the geographical variability in fertility risk. However, it did not disappear entirely. Most notably, the risk of second conception remained higher for couples in the suburbs of Helsinki and in rural areas, but not for couples in the suburbs of other cities and towns.

Model 8, Table 3, separates the risk of second conception for migrants and non-migrants in suburban areas. The patterns for non-migrants were similar to the overall patterns for the suburban population we observed in Model 7, while for migrants the risk levels varied. The particularly high risk for migrants from urban centres to suburbs that was observed for first birth was not evident for second birth, but the risk of second conception was particularly high for migrants to the suburbs of other cities and towns who did not originate in the nearby urban centre.

Again, we further explored the fertility behaviour of suburban in-migrants by considering the timing of childbearing following migration (Figure 2). Similar to first birth there was evidence of a selection effect for migrants from Helsinki into the surrounding suburbs, as the risk of second conception peaked around three months after moving. Interestingly, for in-migrants to the suburbs of other cities and towns who did not originate in the nearby urban centre the risk of second conception increased and remained high into the second year following migration. However, the overall rates of second conception in the suburbs 
were not greatly influenced by the fertility behaviour of migrants, as they formed a small share of the suburban population.

\section{Risk of third birth}

The overall results for third birth were broadly similar to those for first two births, but there were a few noticeable differences. Model 9, Table 4, shows that couples in the suburbs of other cities and towns and those in rural areas had a relatively high risk of third conception as expected, while couples in Helsinki's suburbs displayed similar fertility levels to those living in the urban centre. Again, the inclusion of housing type as a control variable reduced the fertility variation across residential contexts (Model 11, Table 4), although fertility risks remained significantly higher in the suburbs of the other cities and towns and in rural areas than elsewhere.

Model 12, Table 4, provides separate risks of third conception for migrant and nonmigrant couples in suburban areas. The differences between migrants and non-migrants were more substantial for third birth than for previous births, demonstrating that as the family gets larger, fertility and migration decisions are obviously more closely tied. Migrants from both Helsinki and the other city and town centres to their respective suburbs had a much higher risk of third conception than non-migrants in suburban areas, and migrants into the suburbs of other cities and towns who did not originate in the nearby urban centre displayed particularly high risks of a third birth. Overall, therefore, the risks of third birth were especially high for most migrants into suburban areas.

Figure 3 provides the results for the timing of third conception for the suburban inmigrants. There was clear evidence of selection effects for migrants into the suburbs of other cities and towns, who displayed very high risks of third birth in the first quarter of the year following the move regardless of whether they had come from the nearby city centre, or from elsewhere. In addition, we found that couples who had moved from the centre of Helsinki into its suburbs and those who had moved to the suburbs of other towns and cities from origins other than the nearby city centre displayed relatively high third-birth risks in the second and third year after migration. At first, this could be interpreted as evidence of adaptation effects but, perhaps surprisingly, their fertility remained at (or increased to) much higher risks of fertility than experienced by either non-migrant couples or other migrant groups. However, as the number of third-birth 
events for various migrant groups is small the results for the timing of conceptions relative to the moves should be interpreted with some caution.

\section{Summary and discussion}

In this study, we examined childbearing patterns across various residential contexts for different (non)migrant groups. Thus, we have moved beyond the usual urban-rural focus of most previous studies of within country fertility variation by distinguishing between urban centres and suburbs in both cities and towns. A few recent US studies have argued that this is an important geographical distinction (e.g. Albrecht and Albrecht 2004, Heaton et al. 1989, Snyder 2006) but little attention has been given to suburban fertility in Europe. Subsuming suburban areas into cities, as in most previous within-nation studies, may mask the extent of the fertility differentials between city centres and rural areas.

Our results support this argument. First, we observed significant variation in the fertility levels across residential contexts - fertility was higher among couples in suburbs and rural areas and lower in the urban centres, especially Helsinki. This analysis thus demonstrates the distinctiveness of suburban fertility patterns. Second, the fertility variation significantly decreased once we controlled for a range of demographic and socio-economic and housing characteristics, but fertility levels in suburbs still remained higher than in the urban centres. Third, among suburban residents migrants from the urban centre showed systematically higher fertility levels than non-migrants, which could be attributed to the moves prompted by imminent childbearing plans. Nevertheless, fertility levels in the suburbs were not much influenced by selective migrations as the migrant couples formed only a small share of suburban population.

Our study thus showed that much of the fertility variation between the urban centres and suburbs could be attributed to the different demographic and socio-economic characteristics of women residing there and, particularly, to their housing conditions. This raises the question of whether contextual effects are influential once compositional characteristics are accounted for? There are at least two arguments which suggest that further control for compositional characteristics may have explained remaining fertility variation across residential contexts. First, while we controlled for women's education and income in our models, we failed to control for their partner's characteristics, which 
might explain higher fertility for couples in suburban areas. However, we are reassured that the inclusion of data on any partner's education and income would be unlikely to have changed the patterns we observed. Previous research for the Nordic countries shows that the influence of socio-economic characteristics on fertility is very similar for women and men and that there are no important interaction effects between parents' socioeconomic characteristics on their joint childbearing dynamics (Andersson et al. 2005).

Second, it is possible that the higher fertility levels we observed for non-migrants in the suburbs, even after controlling for socio-economic characteristics and housing conditions, could have been influenced by selective moves which were not accounted for in our analysis. Women whose union was formed as a clear step to family formation may have been more likely to start their co-residence in the suburbs whereas women who did not have any childbearing plans may have been more likely to stay in the urban centre with their partner.

On the other hand, it could be argued that our results demonstrate the importance of contextual factors. First, the analyses showed that a significant portion of the variation in first-conception risks across residential contexts could be attributed to the fact that married couples were over-represented in suburban and rural areas. The direction of causality, however, remains far from clear - people might decide to marry because they wished to have children, and marriage could still be seen as a more suitable context for childbearing than cohabitation, or a decision to start childbearing soon could be seen as a reason to "legalise" co-residence of partners (cf. Baizan et al. 2004). Thus there might be some other factors (including contextual factors) which led couples to have their first child and simultaneously form a marriage.

Second, the analyses showed that over-representation of couples in single-family houses was for a major factor influening higher fertility levels in the suburbs and rural areas. On the one hand, housing can still be seen as a proxy of some couple-specific omitted characteristics (e.g. total income or 'family-proneness'). On the other hand, housing per $s e$ is a contextual characteristic as it reflects the living conditions of a couple. Moreover, it cannot be easily separated from the character of the surrounding living environment. While it is possible to live in the urban centre in a single-family house or in the suburbs in a flat, most couples in the suburbs and rural areas are more likely to live in singlefamily houses and couples in urban centres are more likely to live in flats. The inclusion 
of housing in our models could thus be seen as a first step in disaggregating the contextual effects on childbearing behaviour.

In this study we used register data from Finland, which contained detailed partnership, fertility and residential histories for women. As fertility variation across residential contexts is rather similar in the Nordic countries (Kulu et al. 2007a; Kulu et al. 2007b), there is a good reason to believe that overall the results of this study may be applicable to all Nordic countries. Whether they would be replicated in other European or North America contexts would need to be explored. It is likely that in countries where lifecourse related mobility is higher and suburbanisation is more widespread than in Finland (e.g. in the UK or the US) the fertility differences between the urban centres and suburbs may be even larger (cf. Boyle et al. 2007). In that case it is possible that selective migration may have a more influential role.

This study showed that fertility levels vary significantly between urban, suburban and rural areas, and that demographic and socio-economic characteristics of individuals and their housing conditions explained a significant portion, but not all of the variation. Given the importance of housing and residential context as fertility determinants, further research should benefit from more detailed analysis of how housing conditions and residential contexts interact in shaping childbearing patterns of population. Certainly, more studies are required which recognise the value of distinguishing demographic behaviour in urban, suburban and rural areas.

\section{Acknowledgements}

We thank the Max Planck Institute for Demographic Research (MPIDR) for funding, which supported Paul Boyle's research stay at the Laboratory of Contemporary European Fertility and Family Dynamics of the MPIDR. We also thank Statistics Finland for having provided us with the register data used in this study, and Marianne Johnson for valuable suggestions when preparing the data order (TK-53-1662-05). 


\section{References}

Aassve, A., S. Burgess, C. Propper, and M. Dickson. 2006. Employment, family union and childbearing decisions in Great Britain, Journal of the Royal Statistical Society A 169(4): 781-804.

Albrecht, D. E., and C. M. Albrecht. 2004. Metro/nonmetro residence, nonmarital conception, and conception outcomes, Rural Sociology, 69(3): 430-452.

Andersson, G. 2000. The impact of labor-force participation on childbearing behavior: pro-cyclical fertility in Sweden during the 1980s and the 1990s, European Journal of Population 16(4): 293-333.

Andersson, G. 2004. Childbearing after migration: fertility patterns of foreign-born women in Sweden, International Migration Review 38(2): 364-392.

Andersson, G., A.-Z. Duvander, and K. Hank. 2005. Erwerbsstatus und Familienentwicklung in Schweden aus paarbezogener Perspektive, in A. Tölke and K. Hank (Eds.), Männer - Das 'vernachlässigte' Geschlecht in der Familienforschung [Sonderheft 4 der Zeitschrift für Familienforschung]. Wiesbaden: VS Verlag für Sozialwissenschaften, pp. 220-234.

Baizan, P., A. Aassve, and F. C. Billari. 2004. The interrelations between cohabitation, marriage and first birth in Germany and Sweden, Population and Environment 25(6): 531-561.

Billari, F. C., and H.-P. Kohler. 2004. Patterns of low and lowest-low fertility in Europe, Population Studies 58(2): 161-176.

Blossfeld H.-P., and G. Rohwer. 1995 Techniques of Event History Modeling: New Approaches to Causal Analysis. Mahwah, NJ: Lawrence Erlbaum Associates.

Boyle, P. J. 2003. Population geography: does geography matter in fertility research?, Progress in Human Geography 27(5): 615-626.

Boyle, P. J., E. Graham, and Z. Feng. 2007. Contextualising demography: the significance of local clusters of fertility in Scotland. St Andrews: University of St Andrews, Unpublished manuscript.

Caldwell, J. C., and T. Schindlmayr. 2003. Explanations of the fertility crisis in modern societies: a search for commonalities, Population Studies 57(3): 241-263.

Champion, A. G. 2001. Urbanization, sub-urbanization, counterurbanization, and reurbanization, in R. Paddison (Ed.), Handbook of Urban Studies. London: Sage, pp. 143-161.

Coale, A. J., and S. C. Watkins. 1986. (Eds.) The Decline of Fertility in Europe. Princeton: Princeton University Press.

Coleman, D. 2002. Populations of the industrial world - a convergent demographic community?, International Journal of Population Geography 8(5): 319-344.

Courgeau, D. 1989. Family formation and urbanization, Population: An English Selection 44(1): 123-146.

Engelhardt, H., T. Kögel, and A. Prskawetz. 2004. Fertility and women's employment reconsidered: a macro-level time series analysis for developed countries, 19602000, Population Studies 58(1): 109-120.

Frejka, T., and G. Calot. 2001. Cohort reproductive patterns in low-fertility countries, Population and Development Review 27(1): 103-132. 
Fagnani, J. 1991. Fertility in France: the influence of urbanization, in J. Bähr and P. Gans (Eds.), The Geographical Approach to Fertility. Kieler Geographische Schriften 78. Kiel: Geographisches Institut der Universität Kiel, pp. 165-173.

Garrett, E., A. Reid, K. Schürer, and S. Szreter. 2001. Changing Family Size in England and Wales: Place, Class and Demography, 1891-1911. Cambridge: Cambridge University Press.

Goldstein, S., and K. B. Mayer. 1965. Residence and status differences in fertility, The Milbank Memorial Fund Quarterly 43(3): 291-310.

Goldstein, S. 1973. Interrelations between migration and fertility in Thailand, Demography 10(2): 225-241.

Goldstein, S., and A. Goldstein. 1981. The impact of migration on fertility: an 'own children' analysis for Thailand, Population Studies 35(2): 265-281.

Grabill, H. W., C. V. Kiser, and P. K. Whelpton. 1958. The Fertility of American Women. New York: John Wiley \& Sons.

Hank, K. 2001. Regional fertility differences in Western Germany: an overview of the literature and recent descriptive findings, International Journal of Population Geography 7(4): 243-257.

Heaton, T. B., D. T. Lichter, and A. Amoateng. 1989. The timing of family formation: Rural-urban differentials in first intercourse, childbirth and marriage, Rural Sociology 54(1): 1-16.

Hoem, J. M. 1987. Statistical analysis of a multiplicative model and its application to the standardization of vital rates: a review, International Statistical Review 55(2): 119-152.

Hoem, J. M. 1990. Social policy and recent fertility change in Sweden, Population and Development Review 16(4): 735-748.

Hoem, J. M. 1993a. Classical demographic models of analysis and modern eventhistory techniques. IUSSP, 22nd International Population Conference, Montreal, Canada, Volume 3: 281-291.

Hoem, J. M. 1993b. Public policy as the fuel of fertility: effects of a policy reform on the pace of childbearing in Sweden in the 1980s, Acta Sociologica 36: 19-31.

Hoem, J. M., G. R. Neyer, and G. Andersson. 2006a. Education and childlessness: the relationship between educational field, educational level, and childlessness among Swedish women born in 1955-59, Demographic Research 14(15): 331-380.

Hoem, J. M., G. R. Neyer, and G. Andersson. 2006b. Education attainment and ultimate fertility among Swedish women born in 1955-59, Demographic Research 14(16): 381-404.

Hugo, G., A. Champion, and A. Lattes. 2003. Toward a new conceptualization of settlements for demography, Population and Development Review 29(2): 277-297.

Kohler, H.-P., F. C. Billari, and J. A. Ortega. 2002. The emergence of lowest-low fertility in Europe during the 1990s, Population and Development Review 28(4): 641-680.

Kulu, H. 2005. Migration and fertility: competing hypotheses re-examined, European Journal of Population 21: 51-87.

Kulu, H. 2006. Fertility of internal migrants: comparison between Austria and Poland, Population, Space and Place 12(3): 147-170. 
Kulu, H., P. J. Boyle, and G. Andersson. 2007a. Suburban fertility in the Nordic countries. Rostock: Max Planck Institute for Demographic Research, Unpublished manuscript.

Kulu, H., and A. Vikat. 2007. Fertility differences by housing type: the effect of housing conditions or selective moves. MPIDR, Working Paper WP-2007-014. Rostock: Max Planck Institute for Demographic Research. http://www.demogr.mpg.de/papers/working/wp-2007-014.pdf

Kulu, H., A. Vikat, and G. Andersson. 2007b. Settlement size and fertility in the Nordic countries, Population Studies 51(3): 265-285.

Mayer, A., and C. Klapprodt. 1955. Fertility differentials in Detroit: 1920-1950, Population Studies 9(2): 148-158.

Michielin, F. 2004. Lowest low fertility in an urban context: the role of migration in Turin, Italy, Population, Space and Place 10(4): 331-347.

Milewski, N. 2006. First child of immigrant workers and their descendants in West Germany: interrelation of events, disruption, or adaptation? MPIDR Working Paper WP-2006-034. Rostock: Max Planck Institute for Demographic Research. http://www.demogr.mpg.de/papers/working/wp-2006-034.pdf

Miller, L. J. 1995. Family togetherness and the suburban ideal, Sociological Forum 10(3): 393-418.

Mulder, C. H., and M. Wagner. 2001. The connection between family formation and first-time home ownership in the context of West Germany and the Netherlands, European Journal of Population 17(2): 137-164.

Myers, G. C., and E. W. Morris. 1966. Migration and fertility in Puerto Rico, Population Studies 20(1): 85-96.

Neyer, G., and G. Andersson. 2004. Contemporary Research on European fertility: introduction, Demographic Research, Special Collection S3(1): 1-14.

Sharlin, A. 1986. Urban-rural differences in fertility in Europe during the demographic transition, in A. J. Coale and S. C. Watkins (Eds.), The Decline of Fertility in Europe. Princeton: Princeton University Press, pp. 234-260.

Snyder, A. R. 2006. The role of contemporary family behaviors in nonmarital conception outcomes of nonmetro women: comments on Albrecht and Albrecht (2004), Rural Sociology 71(1): 155-163.

Surkyn, J., and R. Lesthaeghe. 2004. Value orientations and the second demographic transition (SDT) in Northern, Western and Southern Europe: an update, Demographic Research, Special Collection S3(3): 45-86.

Szreter, S. 1996. Fertility, Class and Gender in Britain 1860-1940. Cambridge: Cambridge University Press.

Szreter, S., and E. Garrett. 2000. Reproduction, compositional demography, and economic growth: family planning in England long before the fertility decline, Population and Development Review 26(1): 45-80.

Van de Kaa, D. J. 1987. Europe's second demographic transition, Population Bulletin 42: 1-64.

Van de Kaa, D. J. 2001. Postmodern fertility preferences: from changing value orientation to new behaviour, in R. A. Bulatao and J. B. Casterline (Eds.) Global Fertility Transition. Supplement to Population and Development Review 27: 290-331. 
Vikat, A. 2004. Women's labor force attachment and childbearing in Finland, Demographic Research, Special Collection S3(8): 177-212.

Weller, R. H., and L. F. Bouvier. 1972. The three R's: residence, religion, and reproduction, Demography 9(2): 231-240.

Wilson, C. 2001. On the scale of global demographic convergence 1950-2000, Population and Development Review 27(1): 155-172. 
Table 1. Person-years and births by place of residence.

\begin{tabular}{|c|c|c|c|c|}
\hline & $\begin{array}{c}\text { Person- } \\
\text { years } \\
\text { Number }\end{array}$ & Percent & $\begin{array}{c}\text { Births } \\
\text { Number }\end{array}$ & Percent \\
\hline \multicolumn{5}{|l|}{ First birth } \\
\hline Capital city, centre & 16921.14 & 17.3 & 1955 & 13.7 \\
\hline Capital city, suburbs & 16776.95 & 17.1 & 2528 & 17.7 \\
\hline Non-migrants & 14555.41 & 14.8 & 2112 & 14.8 \\
\hline Centre migrants & 1507.57 & 1.5 & 304 & 2.1 \\
\hline Other migrants & 713.97 & 0.7 & 112 & 0.8 \\
\hline Other cities and towns, centres & 42928.05 & 43.8 & 6094 & 42.7 \\
\hline Other cities and towns, suburbs & 12405.25 & 12.7 & 2157 & 15.1 \\
\hline Non-migrants & 10301.10 & 10.5 & 1734 & 12.1 \\
\hline Centre migrants & 1483.71 & 1.5 & 301 & 2.1 \\
\hline Other migrants & 620.43 & 0.6 & 122 & 0.9 \\
\hline Rural areas & 9007.05 & 9.2 & 1548 & 10.8 \\
\hline Total & 98038.44 & 100.0 & 14282 & 100 \\
\hline \multicolumn{5}{|l|}{ Second birth } \\
\hline Capital city, centre & 6320.17 & 12.6 & 1229 & 10.2 \\
\hline Capital city, suburbs & 8959.68 & 17.8 & 2208 & 18.3 \\
\hline Non-migrants & 7266.82 & 14.5 & 1699 & 14.1 \\
\hline Centre migrants & 1262.94 & 2.5 & 372 & 3.1 \\
\hline Other migrants & 429.92 & 0.9 & 137 & 1.1 \\
\hline Other cities and towns, centres & 20550.00 & 40.9 & 4880 & 40.4 \\
\hline Other cities and towns, suburbs & 8829.71 & 17.6 & 2212 & 18.3 \\
\hline Non-migrants & 6818.39 & 13.6 & 1567 & 13.0 \\
\hline Centre migrants & 1459.35 & 2.9 & 455 & 3.8 \\
\hline Other migrants & 551.97 & 1.1 & 190 & 1.6 \\
\hline Rural areas & 5571.58 & 11.1 & 1561 & 12.9 \\
\hline Total & 50231.14 & 100.0 & 12090 & 100.0 \\
\hline \multicolumn{5}{|l|}{ Third birth } \\
\hline Capital city, centre & 4780.01 & 9.5 & 320 & 7.8 \\
\hline Capital city, suburbs & 8928.87 & 17.7 & 629 & 15.3 \\
\hline Non-migrants & 7031.91 & 13.9 & 472 & 11.5 \\
\hline Centre migrants & 1335.96 & 2.6 & 114 & 2.8 \\
\hline Other migrants & 561.00 & 1.1 & 43 & 1.0 \\
\hline Other cities and towns, centres & 19914.16 & 39.4 & 1504 & 36.7 \\
\hline Other cities and towns, suburbs & 10143.77 & 20.1 & 928 & 22.6 \\
\hline Non-migrants & 7299.94 & 14.4 & 614 & 15.0 \\
\hline Centre migrants & 2009.74 & 4.0 & 205 & 5.0 \\
\hline Other migrants & 834.10 & 1.7 & 109 & 2.7 \\
\hline Rural areas & 6780.23 & 13.4 & 718 & 17.5 \\
\hline Total & 50547.03 & 100.0 & 4099 & 100.0 \\
\hline
\end{tabular}


Table 2. Relative risks of conception leading to first birth.

\begin{tabular}{|c|c|c|c|c|c|c|c|c|}
\hline & Model 1 & & Model 2 & & Model 3 & & Model 4 & \\
\hline \multicolumn{9}{|l|}{ Current residence } \\
\hline Capital city, centre & 0.79 & $* * *$ & 0.80 & $* * *$ & 0.84 & $* * *$ & & \\
\hline Capital city, suburbs & 1.04 & & 0.98 & & 0.98 & & & \\
\hline Other cities and towns, centres & 1.00 & & 1.00 & & 1.00 & & & \\
\hline Other cities and towns, suburbs & 1.24 & $* * *$ & 1.13 & $* * *$ & 1.06 & $* *$ & & \\
\hline Rural areas & 1.23 & $* * *$ & 1.09 & $* * *$ & 1.00 & & & \\
\hline Capital city, centre & & & & & & & 0.84 & $* * *$ \\
\hline Capital city, suburbs, non-migrants & & & & & & & 0.97 & \\
\hline Capital city, suburbs, centre migrants & & & & & & & 1.10 & \\
\hline Capital city, suburbs, other migrants & & & & & & & 0.87 & \\
\hline Other cities and towns, centres & & & & & & & 1.00 & \\
\hline Other cities and towns, suburbs, non-migrants & & & & & & & 1.06 & * \\
\hline Other cities and towns, suburbs, centre migrants & & & & & & & 1.13 & $*$ \\
\hline Other cities and towns, suburbs, other migrants & & & & & & & 0.95 & \\
\hline Rural areas & & & & & & & 1.00 & \\
\hline
\end{tabular}

Significance: '*'=10\%; '**'=5\%; '***'=1\%, determined in relation to the risk in 'other cities and towns, centres'.

Models 1: controlled for union duration and the woman's age.

Model 2: additionally controlled for marital status, calendar time, educational level and enrolment, and earnings.

Models 3 and 4: additionally controlled for housing. 
Table 3. Relative risks of conception leading to second birth.

\begin{tabular}{|c|c|c|c|c|c|c|c|c|}
\hline & Model 5 & & Model 6 & & Model 7 & & Model 8 & \\
\hline \multicolumn{9}{|l|}{ Current residence } \\
\hline Capital city, centre & 0.89 & $* * *$ & 0.89 & $* * *$ & 0.95 & & & \\
\hline Capital city, suburbs & 1.07 & $* *$ & 1.05 & $*$ & 1.05 & * & & \\
\hline Other cities and towns, centres & 1.00 & & 1.00 & & 1.00 & & & \\
\hline Other cities and towns, suburbs & 1.08 & $* * *$ & 1.08 & $* * *$ & 1.01 & & & \\
\hline Rural areas & 1.17 & $* * *$ & 1.14 & $* * *$ & 1.06 & * & & \\
\hline Capital city, centre & & & & & & & 0.95 & \\
\hline Capital city, suburbs, non-migrants & & & & & & & 1.05 & \\
\hline Capital city, suburbs, centre migrants & & & & & & & 1.06 & \\
\hline Capital city, suburbs, other migrants & & & & & & & 1.02 & \\
\hline Other cities and towns, centres & & & & & & & 1.00 & \\
\hline Other cities and towns, suburbs, non-migrants & & & & & & & 0.99 & \\
\hline Other cities and towns, suburbs, centre migrants & & & & & & & 1.04 & \\
\hline Other cities and towns, suburbs, other migrants & & & & & & & 1.25 & $* * *$ \\
\hline Rural areas & & & & & & & 1.06 & $*$ \\
\hline
\end{tabular}

Significance: '*'=10\%; '**'=5\%; '***'=1\%, determined in relation to the risk in 'other cities and towns, centres'.

Models 5: controlled for union duration, the woman's age and the age of the first child.

Model 6: additionally controlled for marital status, calendar time, educational level and enrolment, and earnings.

Models 7 and 8: additionally controlled for housing. 
Table 4. Relative risks of conception leading to third birth.

\begin{tabular}{|c|c|c|c|c|c|c|c|c|}
\hline & Model 9 & & Model 10 & & Model 11 & & Model 12 & \\
\hline \multicolumn{9}{|l|}{ Current residence } \\
\hline Capital city, centre & 0.95 & & 0.95 & & 1.01 & & & \\
\hline Capital city, suburbs & 0.96 & & 0.96 & & 0.97 & & & \\
\hline Other cities and towns, centres & 1.00 & & 1.00 & & 1.00 & & & \\
\hline Other cities and towns, suburbs & 1.19 & $* * *$ & 1.18 & $* * *$ & 1.13 & $* * *$ & & \\
\hline Rural areas & 1.28 & $* * *$ & 1.26 & $* * *$ & 1.19 & $* * *$ & & \\
\hline Capital city, centre & & & & & & & 1.01 & \\
\hline Capital city, suburbs, non-migrants & & & & & & & 0.93 & \\
\hline Capital city, suburbs, centre migrants & & & & & & & 1.21 & $*$ \\
\hline Capital city, suburbs, other migrants & & & & & & & 0.91 & \\
\hline Other cities and towns, centres & & & & & & & 1.00 & \\
\hline Other cities and towns, suburbs, non-migrants & & & & & & & 1.06 & \\
\hline Other cities and towns, suburbs, centre migrants & & & & & & & 1.20 & $* *$ \\
\hline Other cities and towns, suburbs, other migrants & & & & & & & 1.49 & $* * *$ \\
\hline Rural areas & & & & & & & 1.18 & $* * *$ \\
\hline
\end{tabular}

Significance: '*'=10\%; '**'=5\%; '***'=1\%, determined in relation to the risk in 'other cities and towns, centres'.

Models 9: controlled for union duration, the woman's age and the age of the second child.

Model 10: additionally controlled for marital status, calendar time, educational level and enrolment, and earnings.

Models 11 and 12: additionally controlled for housing. 


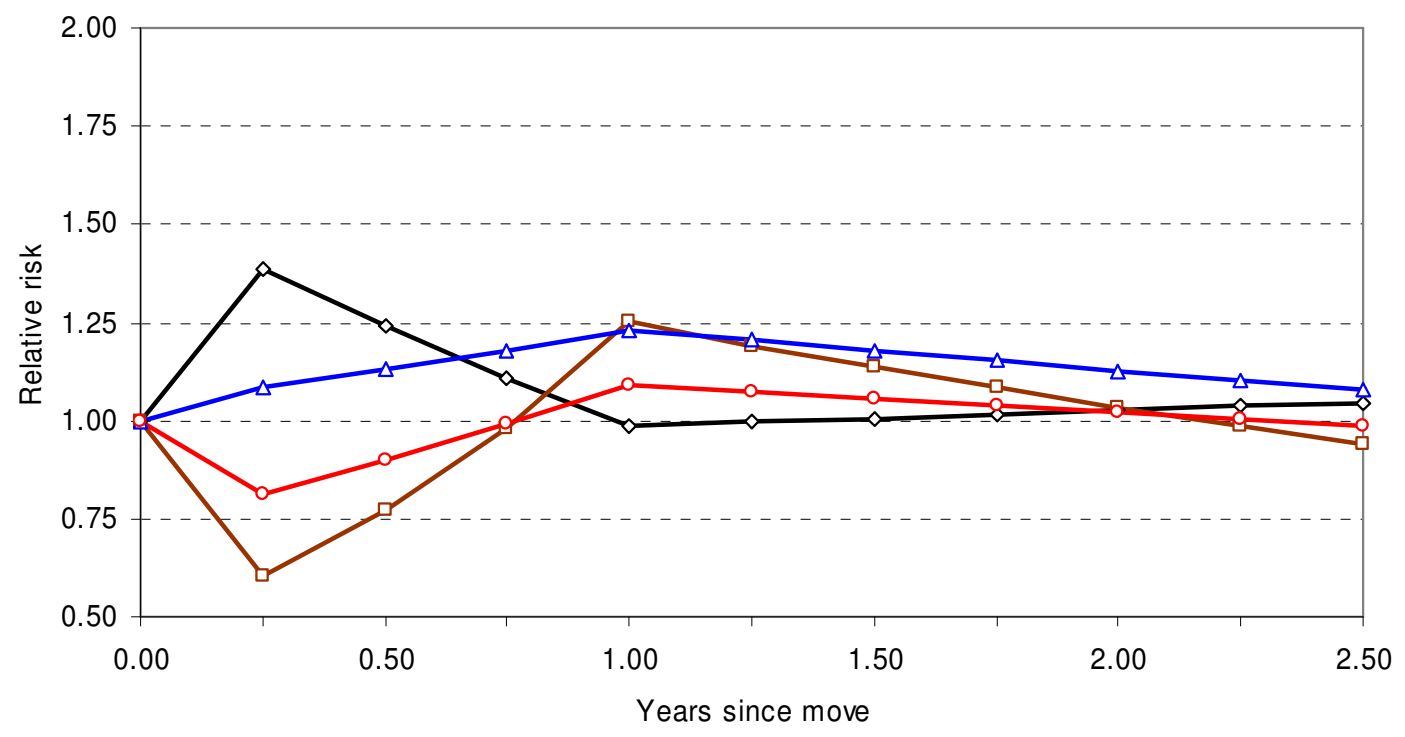

$\neg$ Capital city, suburbs, centre migrants

$\rightarrow-$ Capital city, suburbs, other migrants

$\neg$ Other cities and towns, suburbs, centre migrants

$\ldots$ Other cities and towns, suburbs, other migrants

Figure 1. Relative risks of conception leading to first birth (extended version of Model 4). 


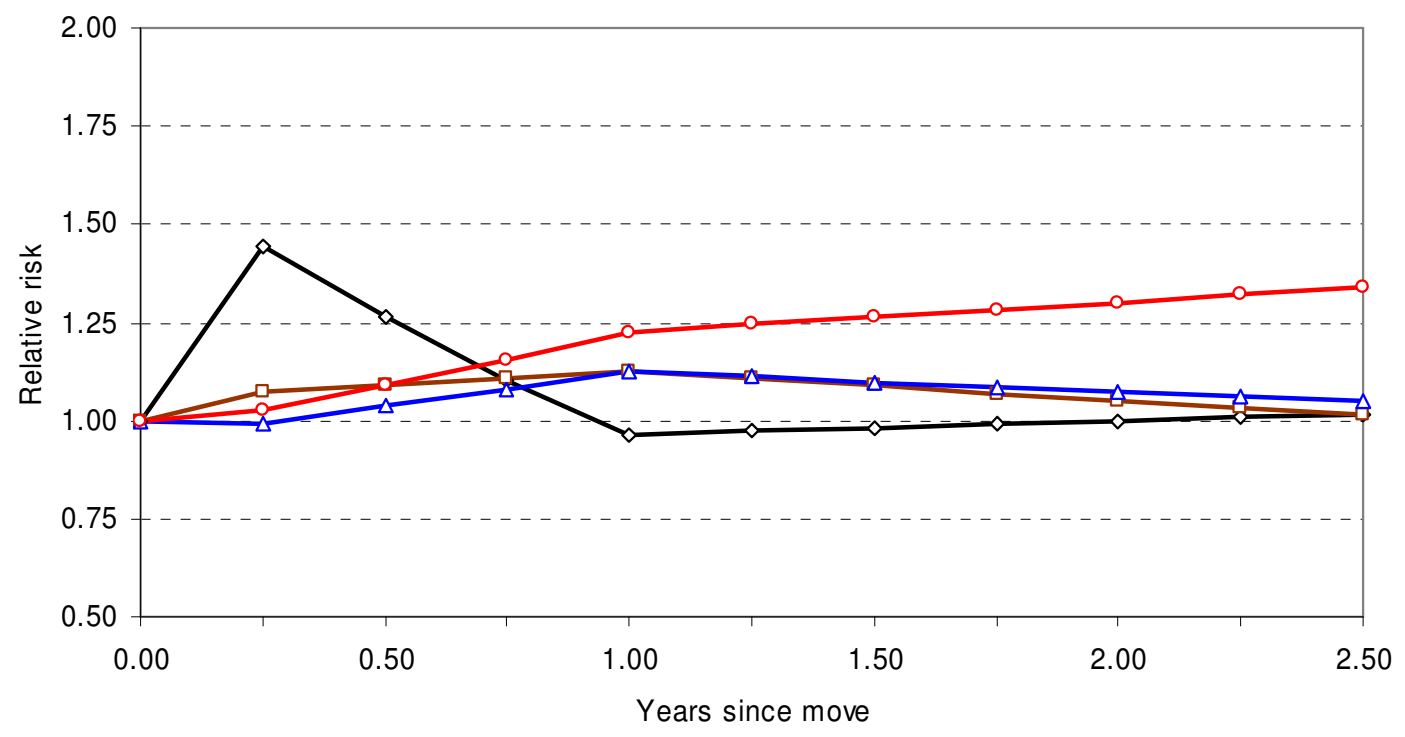

$\prec$ Capital city, suburbs, centre migrants

$\rightarrow-$ Capital city, suburbs, other migrants

$\rightarrow$ Other cities and towns, suburbs, centre migrants

- $\ldots$ Other cities and migrants, suburbs, other migrants

Figure 2. Relative risks of conception leading to second birth (extended version of Model 8). 


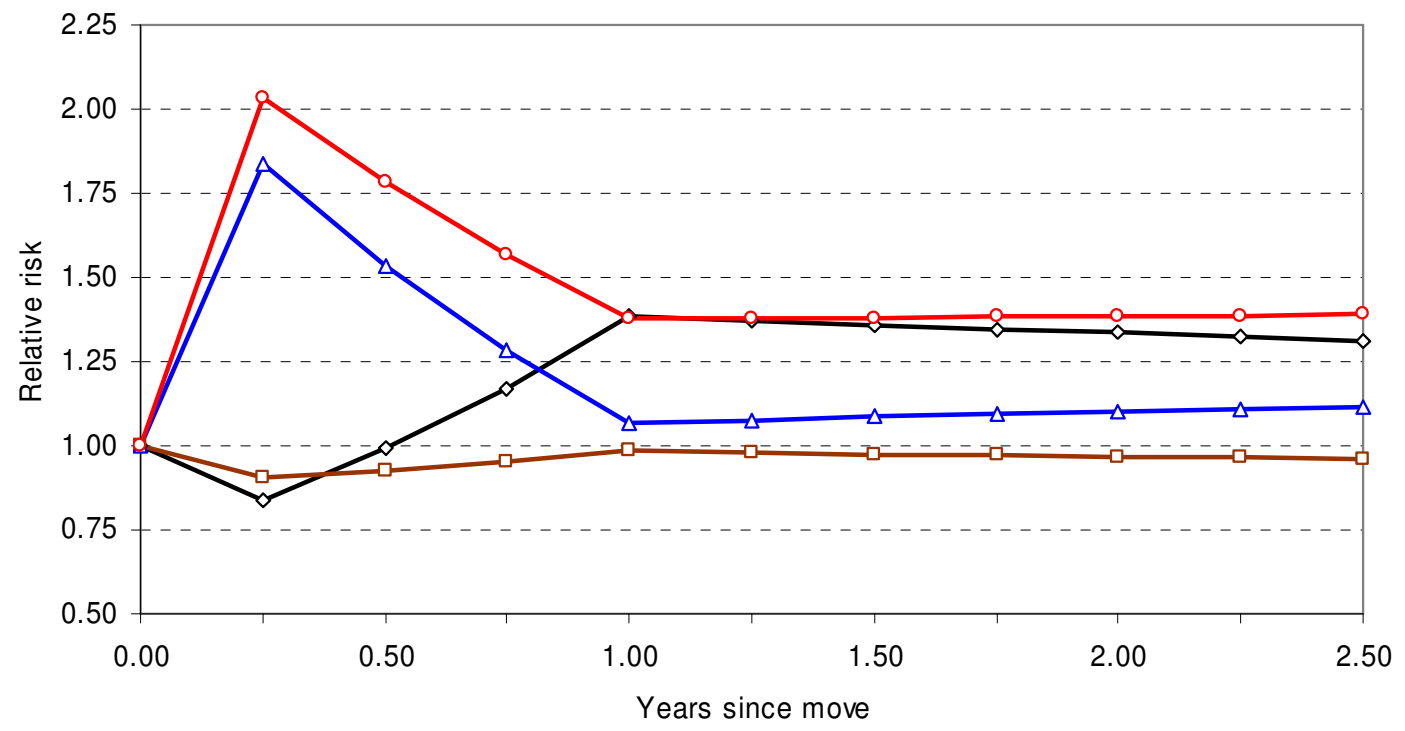

$\prec$ Capital city, suburbs, centre migrants

$\rightarrow-$ Capital city, suburbs, other migrants

$\neg$ Other cities and towns, suburbs, centre migrants

$\ldots$ Other cities and towns, suburbs, other migrants

Figure 3. Relative risks of conception leading to third birth (extended version of Model 12). 